\title{
O DISCURSO INCLUSIVO: UMA ANÁLISE CRÍTICA DA REPRESENTAÇÃO DA MULHER NEGRA E DA PLURICULTURALIDADE EM UM LIVRO DIDÁTICO PARA O ENSINO MÉDIO
}

\section{INCLUSIVE DISCOURSE: A CRITICAL ANALYSIS OF THE REPRESENTATION OF BLACK WOMEN AND PLURICULTURALISM IN A TEXTBOOK FOR HIGH SCHOOL}

\author{
Anna Carolina Barbosa Silva* \\ Claudia Cristina Mendes Giesel ${ }^{* *}$
}

Resumo: Os livros didáticos têm extrema importância no ambiente escolar, pois muitas vezes é o único instrumento disponível para o professor utilizar, principalmente em aulas de língua estrangeira. Entretanto, esse material pode reproduzir preconceitos e imagens estereotipadas de diversas minorias, inclusive de mulheres negras, além de apenas representar as culturas americana e inglesa, sem considerar as demais. Dessa maneira, o presente trabalho tem como objetivo analisar um livro didático de inglês direcionado para alunos que estudam o segundo ano do Ensino Médio, Voices Plus (2016), cujo autor, Rogério Tilio, possui várias publicações criticando a falta de representação e de pluriculturalidade em livros didáticos. A intenção é verificar se ele reproduz em seu livro as críticas dos seus trabalhos. Para tal, alguns fragmentos em que aparecem mulheres negras e culturas diversificadas foram selecionados para análise, que será realizada com base na Análise Crítica do Discurso e a teoria tridimensional de Fairclough (2001), englobando texto, prática discursiva e social para descobrir práticas hegemônicas. Por fim, para dar embasamento a esse trabalho, as obras de pesquisadores renomados como Ferreira (2013), Hall (2008), Van Dijk (2008) e Silva (2011) foram utilizadas. Os resultados alcançados demostram que Tílio exibe em seu livro didático uma representação positiva de mulheres negras e de pluriculturalidade, estando de acordo com as críticas de seus trabalhos.

Palavras-chave: Livro Didático; Representação; Mulheres Negras.

\footnotetext{
"Graduada em Letras - Português/Inglês pela Universidade Veiga de Almeida, UVA/RJ, Brasil. Mestrado em andamento em Linguística pela Faculdade de Letras da Universidade de Lisboa. Email: annacsilva@edu.ulisboa.pt.

"'Doutora em Educação, mestre em linguística aplicada, coordenadora e professora do Curso de Letras modalidade EAD da Universidade Veiga de Almeida. Email: claudia.giesel@uva.br
} 
ABSTRACT: Textbooks are extremely important in school environment, because most times are the only instrument available for the teacher to use, mainly in foreign language classes. However, this material might many times reproduce prejudice and stereotyped images of black women, besides of o represent only American and English culture, without considering the others. Thus, the present work has the objective to analyze an English as a Foreign Language textbook for the second year of high school, Voices Plus (2016), which author, Rogério Tilio, has many publications criticizing the lack of representation and pluriculturalism in textbooks. The proposal is to verify if it he reproduces in his book the critics of his works. To do so, some fragments where black women and cultural diversity appear were selected for analyzes, that will be made based in the Discourse Analysis and Fairclough's (2001) Three-Dimensional, encompassing text, discursive practices and social practices to find hegemonic practices. Lastly, to support this paper, the work of renowned researchers like Ferreira (2013), Hall (2008), Van Dijk (2008) and Silva (2011) were used. The results inform that Tílio shows in his textbook a positive representation of black women and pluriculturalism, in agreement with the criticism of his works.

KEYWORDS: Textbook; Representation; Black Women.

\section{INTRODUÇÃo}

O livro didático é um instrumento muito utilizado em ambiente escolar, principalmente em aulas de língua estrangeira por sua facilidade e pela praticidade oferecida aos professores para ensinar o conteúdo programado para os alunos. No entanto, muitos deles possuem conteúdos que transmitem ideias retrógradas e preconceituosas, representando de maneira errônea mulheres negras e outras minorias, prejudicando os estudantes e professores que os utilizam.

Dessa forma, este trabalho tem como objetivo analisar o livro didático Voices Plus (2016), para o segundo ano do ensino médio, utilizado em uma escola pública, localizada no Estado do Rio de Janeiro. Foi organizado pelo autor Rogério Tílio e é usado por cerca de 70 estudantes do colégio, que têm acesso ao material graças ao Programa Nacional do Livro Didático.

Almeja-se, nesta análise, a identificação da existência ou não de representações positivas de mulheres negras em fragmentos selecionados do livro em que aparecem imagens de mulheres negras e textos sobre outras culturas. A grande maioria dos materiais de língua inglesa mostram mulheres negras em posição inferior, enquanto outras culturas diferentes da americana e inglesa são consideradas exóticas e menos desenvolvidas.

Primeiramente, será apresentado um estudo e pesquisa com trabalhos sobre livro didático, representação de mulheres negras, Análise Crítica do Discurso, racismo e hegemonia. Ferreira (2013), Fairclough (2001), Van Dijk (2008) e Silva (2011) são alguns dos autores que constituem o embasamento teórico deste trabalho, que tem propósito de somar aos estudos sobre educação e preconceito no livro didático. A metodologia utilizada para analisar o livro foi a Análise Crítica do Discurso, desenvolvida por Fairclough (2001). 


\section{DisCUSSÃo TEÓRICA: LIVRO DIDÁTICO, IDEOLOGIA E A REPRESENTAÇÃo DA MULHER NEGRA}

A autoestima, a identidade e o caráter dos adolescentes que utilizam o livro didático são moldados pela sua vivência e pelo conteúdo que o material reproduz, pois o entenderão como correto e exemplo a ser seguido. Ele é o recurso mais utilizado em sala de aula por professores pela sua praticidade, principalmente quando se trata da disciplina de língua estrangeira. "Instrumento básico e, muitas vezes o único meio de trabalho do professor de língua estrangeira da escola pública são os livros didáticos de língua estrangeira”. (FERREIRA; CAMARGO, 2013, p. 178).

O livro didático de inglês é feito de maneira eurocêntrica, focado na cultura dos Estados Unidos e Inglaterra, países que têm inglês como língua nativa, invisibilizando as demais. Silva (2017) escreve que o livro didático é "inserido em uma sociedade enraizada em uma cultura branca e eurocêntrica, que impõe uma relação de poder determinada pela cor/etnia” (SILVA, 2017, p. 2). O material sofre influência desta cultura predominantemente centrada nos padrões europeus.

Em sala de aula, o instrumento básico dos professores é o livro didático (LD). Por este motivo, ele deveria ter um conteúdo que aborde e valorize a diversidade étnico-racial. Quando isto não ocorre, o LD acaba se tornando veículo transmissor de preconceitos e ideias desse teor aos alunos que estudam o livro.

O LD de língua estrangeira é carregado de verdades e é autoritário (FERREIRA; CAMARGO,2013). Quando o professor não entende ou não reflete sobre o material utilizado e as ideologias contidas nele e, consequentemente, não promove discussões sobre o conteúdo utilizado, o livro com representações equivocadas irá prejudicar diretamente o caráter e a identidade dos alunos.

A identidade, segundo Hall (2011), é construída com o tempo e, apesar de individual, é transformada de acordo com as influências que cercam uma pessoa. Não é estática e nem definida biologicamente, mas sim, historicamente. Há diversas identidades dentro de nós, como a mulher negra que tem sua identidade de gênero, como mulher e, a negra, por sua raça.

A escola é uma grande influenciadora da identidade e caráter dos indivíduos em formação, pois é onde as crianças e os adolescentes passam a maior parte do dia. Quando não há discussões envolvendo a cultura e diversidade negra em sala de aula, a consequência é indivíduos que reproduzem preconceitos e estereótipos contra pessoas negras fora e dentro do ambiente escolar (WATTHIER, 2008).

Ainda assim, temas sobre diversidade de gênero, raça e sexualidade são tratados como tabu no Brasil, mesmo com pesquisas demonstrando a necessidade destas discussões no ambiente escolar. 
[...] como possibilidade de se repensar, desconstruir e reinventar as normas sobrepostas para as identidades de gênero, de raça e de sexualidade, numa tentativa de colaborar para a construção de uma sociedade mais inclusiva, acolhedora e democrática, na qual as diferenças sejam vistas e compreendidas como fonte de enriquecimento social, e não como a causa de sofrimento, de violência e de exclusão. (SENE; FERREIRA, 2018, p. 312).

Portanto, a falta de representatividade no livro didático e de discussões em sala de aula sobre racismo transformam alunos em indivíduos que reproduzem preconceitos.

O professor de língua inglesa pode utilizar o livro didático como uma ferramenta a mais para sua ação em sala e não como principal instrumento de ensino. Os alunos, ao receberem informações contidas no livro didático, que apresentam aspectos sobre uma nova cultura, precisam ser conscientizados sobre a pluralidade cultural, a fim de que não desenvolvam uma visão limitada do assunto, criando a falsa impressão de superioridade de uma cultura em relação a outras. (FARIAS; FERREIRA, 2014, p. 58).

Por este motivo, é importante trazer à sala de aula conteúdo sobre pluriculturalidade, para, dessa forma, o aluno não ter a concepção de que uma cultura é melhor ou pior do que a outra. É trabalho do professor identificar estas discriminações, e notá-las neste material.

É importante um olhar reflexivo sobre a dinâmica existente dentro de uma sala de aula, buscando perceber no processo ensino-aprendizagem o limite entre o significativo e o cômodo. Muitas ações em sala de aula têm se tornado automáticas, orientadas por livros que não oportunizam ao aluno o exercício da reflexão e cidadania. (FARIAS; FERREIRA, 2014, p. 63).

Rogério Tilio é o autor do livro didático que será analisado neste trabalho. Ele escreveu diversos estudos e artigos sobre os materiais didáticos de inglês utilizados em escolas, criticando a percepção de que o livro tem maior relevância no ensino do que o próprio professor. "Ao invés de auxiliar o professor no cumprimento de um programa pedagógico, o livro didático de ensino de língua estrangeira vem, muitas vezes, tomando o lugar do próprio programa" (TILIO, 2010, p. 168). Também revela como o discurso destes livros pode construir a identidade dos alunos.

Para o autor, certos posicionamentos do material podem prejudicar a identidade em formação dos alunos, pois apenas uma é demonstrada como certa.

[...] induzindo-os a adotar determinadas identidades que podem parecer-lhes as certas, as socialmente aceitas, e muitas vezes levando-os a reprimir suas verdadeiras identidades, que podem não lhes parecer legitimadas pelo livro. A exposição a determinados discursos, preconceituosos, por exemplo, pode reprimir a liberdade de construção de identidades de alguns alunos. (TILIO, 2010, p. 170). 
Os discursos preconceituosos e racistas prejudicam a formação da identidade dos alunos, pois eles legitimam apenas uma visão do mundo, não dando importância às demais.

Tilio em seus artigos $(2009,2010)$ analisa os livros didáticos e busca revelar as ideologias veiculadas por eles. Enfoca também a formação de identidades sociais, pois revela as crenças inerentes a estes livros - crenças dos autores em relação ao mundo que podem estar sendo perpetuadas através dos livros didáticos." (TILIO, 2009, p. 49).

O autor acredita que o livro didático, por ser o principal instrumento em sala e se sobrepor à autoridade do professor nesse ambiente, tem o poder de prejudicar os alunos "não apenas influenciando sua visão de mundo, mas também, os induzindo a adotar determinadas identidades hegemônicas que podem lhes parecer as certas, as socialmente aceitas" (TILIO, 2009, p. 49).

Em suas análises, verifica a visão do mundo dos livros, que normalmente é a eurocêntrica e a norte americana, sem preocupação com as demais culturas. Tilio também pesquisa sobre a relação de gênero e sexualidade no material didático de inglês. Em uma das imagens de uma das análises, por exemplo, há um homem branco com uma família branca, aparentemente heterossexual, em uma casa confortável e com condição financeira estável. Esse homem é considerado o mais feliz do mundo. "Portanto, mesmo que de forma subliminar, o livro didático associa a felicidade às convenções sociais hegemônicas da família tradicional, com um casamento heterossexual, filhos e estabilidade material." (TILIO, 2010, p. 51). Qualquer modo de vida diferente deste compromete a felicidade.

A mulher é excluída desta narrativa, sendo apenas submissa ao homem e cuidando dos filhos. O autor observa que na maioria dos livros ocorre uma dicotomia dos gêneros feminino e masculino, de estereótipos e de senso comum sobre eles, como a mulher sendo dona de casa, gostando de fazer compras e o homem como o provedor da casa. A sexualidade quase não é abordada em livros didáticos.

Portanto, Rogério Tilio (2016) preocupa-se com as questões sociais, com as representações e com o conteúdo do livro, pois acredita que o material utilizado em sala influencia na formação das identidades dos alunos. Concorda que é importante que não haja figuras estereotipadas ou falta de representação de minorias.

\section{DiscURSO: UMA TEORIA CRÍTICA}

A teoria que foi utilizada para elucidar essa pesquisa foi a Análise Crítica do Discurso. A ACD surge internacionalmente com base nos trabalhos dos teóricos Van Dijk (2008), Fairclough (2001), entre outros. Para Van Dijk (2008), a ACD é um tipo de investigação analítica discursiva que estuda principalmente "o modo que o abuso de poder, a dominação e desigualdade são representados, reproduzidos e combatidos por textos orais e escritos no contexto social e político". (VAN DIJK, 2008, p. 144). 
A ACD irá, dessa forma, desconsiderar os pensamentos anteriores que se baseavam apenas no discurso isolado sem considerar fatores externos. Alguns deles são a intenção e o poder de quem está escrevendo determinado texto, o público para o qual está sendo direcionado determinado discurso, as relações de poder e problemas sociais.

A Análise Crítica do Discurso pretende, principalmente, desvelar relações injustas de poder, e "construções ideológicas opacas nos discursos produzidos, sobretudo pela mídia" (RODRIGUES, 2009, p. 101). O discurso é socialmente construído e molda-se de acordo com as práticas da sociedade, inclusive os discursos acadêmicos. Ao invés de escrever a respeito do discurso, a ACD explica sobre ele e sobre as relações de poder realizadas.

Van Dijk (2008) resume os fundamentos da ACD, são eles: abordagem de problemas sociais; existência de relação entre o texto e a sociedade; o discurso realiza um trabalho ideológico; é uma forma de ação social; as relações de poder são discursivas e o discurso é histórico. O contexto e o momento histórico em que o texto é escrito são essenciais para a sua análise, pois o discurso é feito a partir deles.

As relações de poder são um dos principais temas quando se trata de ACD e discute-se, principalmente, o poder social de grupos e instituições. Um grupo pode ter controle sobre a mente e sobre os atos de outro grupo por meio do discurso, sendo estes grupos grandes ou pequenos. Van Dijk (2008) ainda afirma que a habilidade de manter este controle está ligada à existência de uma base de poder, que permite o acesso privilegiado a vários recursos, como o status, a fama, o dinheiro e a "cultura".

Segundo a teoria de Fairclough (2001), denominada teoria Social do Discurso, existem três aspectos dos efeitos de construção do discurso: primeiramente, contribui para a construção das identidades sociais e posições de sujeito, para a relação social entre as pessoas e para os sistemas de conhecimento e crença.

Estes aspectos correspondem às três funções da linguagem, respectivamente: "identitária", "relacional" e "ideacional". A identitária é sobre como as identidades sociais são inseridas no discurso; a relacional é sobre como é representada a relação entre os indivíduos do discurso; e a ideacional é sobre como o texto representa e entende o mundo e suas relações.

Fairclough (2001), entretanto, afirma que sua teoria é ligada ao discurso como prática política e ideológica. Ele define tais práticas como:

O discurso como prática ideológica constitui, naturaliza, mantém e transforma os significados do mundo de posições diversas nas relações de poder. Como implicam essas palavras, a prática política e a ideológica não são independentes uma da outra, pois a ideologia são os significados gerados em relações de poder como dimensão do exercício do poder e da luta pelo poder. (FAIRCLOUGH, 2001, p. 94).

A ideologia é gerada em relações de poder, normalmente pelos grupos que o detêm. 
Ainda segundo Fairclough (2001), o discurso é semelhante a outras formas de práticas sociais, como a prática discursiva citada por ele, que está diretamente ligada à forma linguística. Contudo, a prática social (política, ideológica) é uma dimensão do evento discursivo, e este encontra-se dentro do discurso, todavia, ele argumenta que isto não é suficiente para o entendimento de prática social e discursiva:

Essas duas dimensões são mediadas por uma terceira, que examina o discurso especificamente como prática discursiva. "Prática discursiva" aqui, não se opõe à "prática social": a primeira é uma forma particular da última. Em alguns casos, a prática social pode ser inteiramente constituída pela prática discursiva, enquanto em outros, pode envolver uma mescla de prática discursiva e não-discursiva. A análise de um discurso particular, como exemplo de prática discursiva, focaliza os processos de produção, distribuição e consumo textual. Todos esses processos são sociais e exigem referência aos ambientes econômicos, políticos e institucionais, particulares leis, às quais o discurso é gerado. (FAIRCLOUGH, 2001, p. 99).

Fairclough (2001) cria, portanto, a concepção tridimensional do discurso, representada na figura a seguir:

Figura 1.1: Modelo tridimensional de Fairclough (2001)

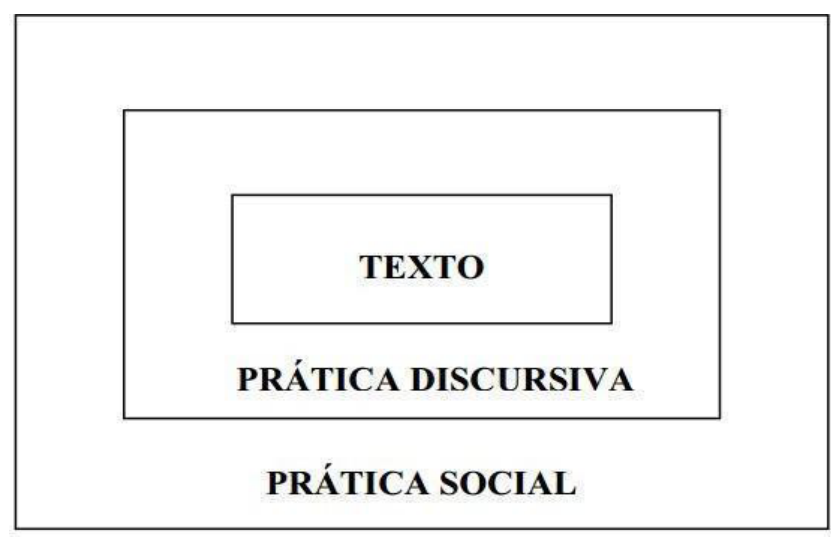

Este modelo tenta exemplificar as três concepções analíticas, indispensáveis à Análise do Discurso. A prática social está dentro tanto da prática discursiva quanto do texto e, de maneira inconsciente, ela molda as práticas dos indivíduos que produzem e distribuem determinado discurso, com base nas relações de poder e por estruturas sociais. Em contrapartida, a prática dos indivíduos também tem impacto e muda a prática social, as lutas sociais e as relações sociais, conforme Fairclough (2001).

A Análise Crítica do Discurso será a principal teoria para a compreensão, de maneira crítica, do livro didático a ser analisado. Será avaliado o conteúdo dele e verificado se contém 
discursos preconceituosos e hegemônicos, prejudiciais para o desenvolvimento da identidade dos alunos.

\section{Metodologia E ANÁLISE DE DAdos}

Nesta sessão, serão apresentadas a metodologia e a análise dos dados obtidos na verificação do livro didático de inglês de Rogério Tilio, Voices Plus (2016), destinado ao segundo ano do ensino médio. O livro de Tilio integra o Programa Nacional do Livro e do Material Didático e é distribuído em escolas públicas. Foram analisadas qualitativamente as imagens e textos segundo à Análise Crítica do Discurso, formulada por Fairclough (2001) e apresentada anteriormente.

\section{Metodologia}

O objetivo desta pesquisa é analisar o livro didático de língua inglesa do autor Rogério Tilio, verificar as imagens e textos que contidos no material para examinar como e se mulheres negras são representadas. O autor é engajado em causas sociais e é a favor de diferentes visões culturais em livros didáticos, portanto é esperado que o livro escrito por ele reflita esta visão e inclua essa minoria positivamente.

Quanto à natureza, aos objetivos e aos procedimentos, este trabalho é, respectivamente, básico, qualitativo, descritivo e documental, com base na explicação dada por Gil (1991) em seu livro Métodos e Técnicas de Pesquisa Social. O corpus que foi instrumento da análise é o livro de Rogério Tilio, Voices Plus (2016), para o segundo ano do Ensino médio.

A análise foi realizada com base na Análise Crítica do Discurso e no modelo tridimensional proposto por Fairclough (2001) com suas três dimensões discursivas: o texto, a prática discursiva e a prática social.

O livro Voices Plus é utilizado e foi distribuído nas escolas públicas estaduais para o uso dos alunos. Ele passou por uma criteriosa avaliação do ministério da educação e integra o Programa Nacional Do Livro Didático (PNLD). A coleta de dados pretende verificar se o conteúdo do livro tem representatividade de mulheres negras e se elas são colocadas em posição inferior à raça branca e aos homens.

Foram analisados as imagens e os textos apresentados no livro, e os critérios para a análise foram a frequência que mulheres negras e outras culturas aparecem e como esta representação acontece. É esperado que o livro de Tilio revele uma imagem positiva de mulheres negras e represente outras culturas positivamente, pois em seus trabalhos anteriores, ele considera a representação e valorização das minorias, repudia o racismo e os demais preconceitos. 


\section{ANÁLISE DE DAdos}

O livro didático de língua inglesa a ser analisado, segundo o modelo tridimensional de Fairclough (2001), é Voices Plus, de Rogério Tilio (2016). Como demonstrado no final da seção anterior, Tilio é um autor que tem consciência sobre minorias e procura criticar, em seus trabalhos, preconceitos e práticas injustas em livros didáticos. Portanto, é esperado que nesta análise seja revelada uma posição mais inclusiva do autor, maior representação de mulheres negras e de diferentes culturas.

Primeiramente, serão descritos os fragmentos do livro que foram analisados e considerados importantes, para posteriormente dar início à análise segundo o Modelo Tridimensional de Fairclough (2001). O primeiro capítulo do livro de Tilio é sobre aquecimento global e demonstra uma conscientização sobre o planeta Terra. Em outra atividade do mesmo capítulo, há um debate sobre a globalização e seus lados positivos e negativos, para dividir as opiniões dos alunos e para que um debate sobre o assunto seja possível.

O principal assunto do primeiro texto ilustrado com uma imagem de pessoas é sobre a internet e o direito de todos de ter acesso a ela. Na imagem, há uma turma de pessoas negras, com foco em um menino olhando para trás. No texto, é informado como os países africanos sofrem com a corrupção e, por esse motivo, a tecnologia não é tão avançada como deveria ser.

O próximo texto também é sobre o direito ao acesso à internet e todas as seis pessoas representadas no plano principal são negras, entre elas, três mulheres e três homens. Comentase sobre a importância da internet e seus benefícios para a sociedade. Entre as mulheres negras, há duas meninas em sala de aula com o hijab, característico da religião muçulmana e uma médica negra atendendo um menino, como mostra a figura a seguir:

Figura 2: a médica atende o menino em um hospital.

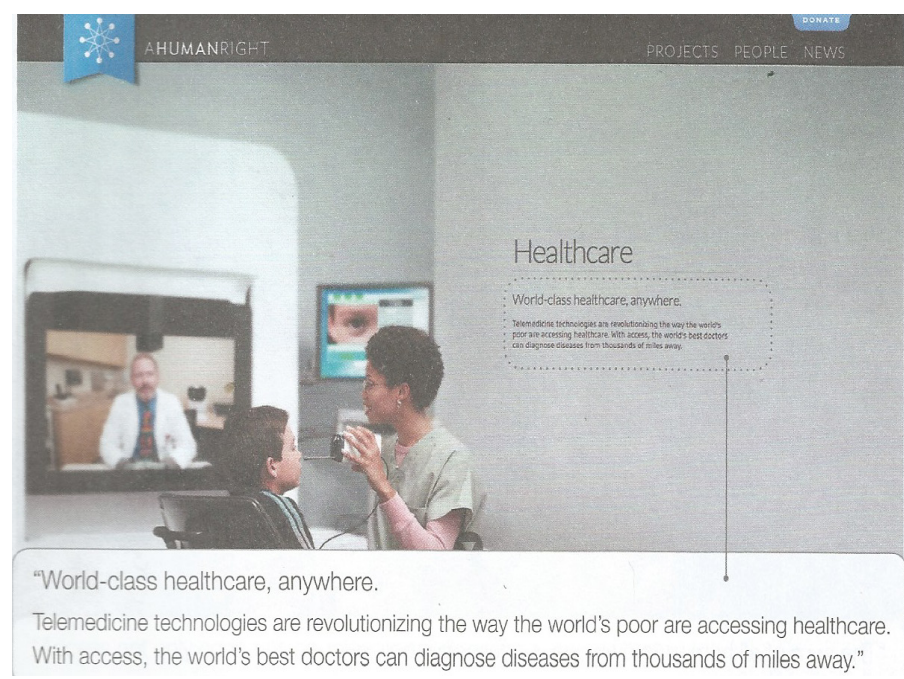


Na próxima atividade, uma professora negra aparece explicando a matéria para uma menina branca em uma sala de aula. Posteriormente, a introdução do segundo capítulo é sobre manifestações artísticas. Há diferentes representações de artes além das que sempre são apresentadas em livros didáticos de inglês, como americana e inglesa. Há também demonstrações artísticas da cultura indígena e indiana.

Ainda no mesmo capítulo, o autor cita e conta a história de algumas peças musicais, entre elas: "Os miseráveis" e "Cats", famosas na Broadway, nos Estados Unidos e na Europa. Um dos musicais citados é uma adaptação musical de "Casa Grande e Senzala”, de Gilberto Freyre, livro que conta a história do Brasil em uma visão não-eurocêntrica, diferente da que está nos livros de história.

Nos próximos capítulos, há outras imagens de mulheres negras em situações positivas, como uma senhora escutando rádio; uma mulher e um homem negros, vestidos de roupas sociais em um lugar que parece um escritório, apertando as mãos. O tema desta unidade é "línguas".

Em uma atividade deste capítulo, o tema principal são as leis de Jim Crow, que segregaram as pessoas de cor das brancas nos Estados Unidos e sobre o racismo que existia na época, com imagens em preto e branco, ilustrando esse triste momento da história.

Em outro texto do mesmo exercício, o autor apresenta uma pesquisa da sociolinguística sobre uma variedade da língua inglesa "African-American Vernacular English", que em tradução livre significa "Inglês vernáculo afro-americano". Três pessoas qualificadas, de forma diferente, falam sobre o uso desta variedade nas escolas. São duas mulheres e um homem, todos negros. Uma delas é diretora de um colégio e a outra é psicóloga educacional, como mostra a imagem a seguir. O homem é professor de Linguística na Universidade de Chicago.

Figura 3: pessoas negras em posição de destaque, comentando a variedade linguística tema da atividade. (Os comentários dos três estão no áudio do CD do livro).

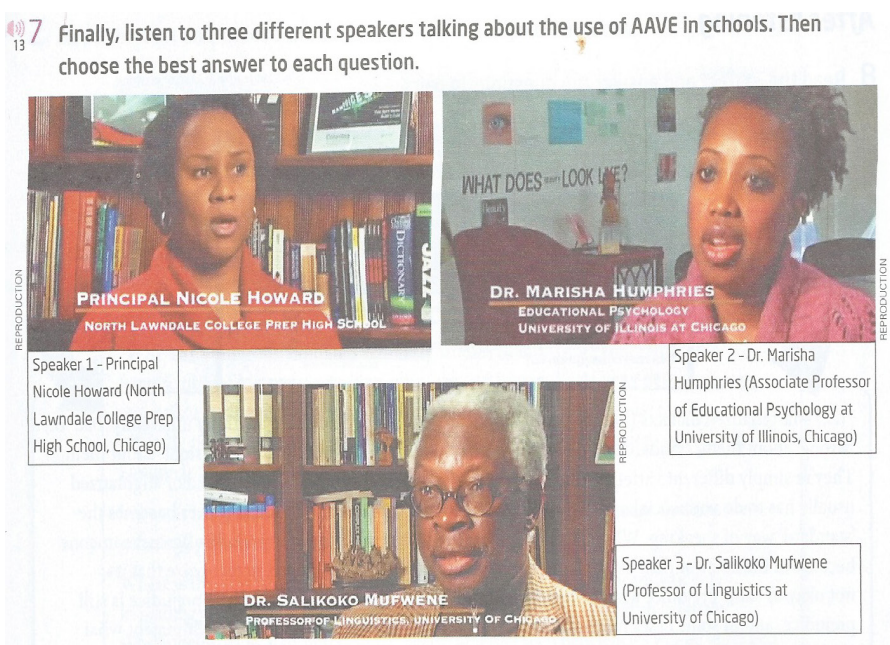


A variedade linguística dos negros nos Estados Unidos, segundo o material, foi vista com preconceito e como uma forma errada de falar inglês, mesmo sendo apenas uma das variedades linguísticas da língua inglesa. O homem negro que comenta sobre ela é Doutor em Linguística, tem autoridade e conhecimento para dizer que é apenas uma entre tantas outras e que considerar este dialeto errado está relacionado com ideologias racistas.

No mesmo capítulo sobre línguas, há um texto sobre o território africano e seu processo de invasão/colonização pelos europeus, no período entre 1881 e 1914. Segundo o texto, em 1870 só $10 \%$ do continente africano era de domínio europeu e, em 1914, esse número pulou para 90\%. Após esse texto, há perguntas sobre as línguas da África e são demonstradas duas perspectivas de homens negros e africanos sobre o assunto.

Neste capítulo, além de discutir sobre os dialetos africanos e a variação linguística dos negros nos Estados Unidos, há uma reflexão sobre a cultura do Brasil e de outros países da América do Sul, que para a maioria das pessoas fala apenas português e espanhol. É observado que o continente tem várias línguas. Questiona-se se os alunos sabiam deste fato e o que poderia ser feito para aumentar o conhecimento das pessoas sobre essas diferentes línguas.

Ao final do livro, há informações sobre a linguagem do corpo, sinais de trânsito e suas diferenças em outras línguas e países, sem nenhuma representação de seres humanos para ilustrar os próximos exercícios, que são questões de ENEM e de outros vestibulares conhecidos no Brasil.

A análise do livro de língua inglesa de Tilio (2016) com base na ACD de Fairclough (2001) e em seu Modelo Tridimensional, inicia-se com a primeira dimensão, a textual. Ela diz respeito às escolhas lexicais e gramaticais feitas pelo autor. Segundo Resende e Ramalho (2004, p. 187), "O modelo de análise do texto é pormenorizado em categorias. São categorias da análise textual, o vocabulário, a gramática, a coesão e a estrutura textual.”

Portanto, nos textos, os léxicos transmitem a ideia de igualdade de mulheres negras em relação às outras personalidades representadas no livro. No que diz a respeito de a imagens, não há nenhuma figura em que aparece mais de uma pessoa, em que uma mulher negra não esteja presente no grupo. Observa-se que há uma preocupação em demonstrar todas as raças e gêneros nas imagens.

Esse é um ponto positivo em relação aos demais materiais didáticos de língua estrangeira, pois ainda há muita discriminação de gênero nas imagens neles presentes, como pontua Pereira (2009).

Muitos materiais didáticos utilizados para o ensino de língua materna e/ ou língua estrangeira, assim como de outras disciplinas do currículo escolar, reproduzem em seus textos escritos e/ou imagéticos e, por vezes, até mesmo na destinação de seu espaço e na referência a personagens fictícios ou reais, a discriminação de gênero observada no tratamento de homens e mulheres. (PEREIRA, 2009, p. 5). 
Ainda sobre a dimensão textual de Fairclough (2001), em relação aos léxicos utilizados, no último capítulo do livro sobre linguagens, Tilio escolhe colocar diversas culturas diferentes para representar as várias línguas existentes no mundo, incluindo as culturas indígenas e africanas, normalmente excluídas.

No texto "A representação do mundo no livro didático: uma abordagem sócio discursiva", Tílio (2010) critica a visão eurocêntrica que os materiais de língua estrangeira reproduzem e a ideia de mundo globalizado com apenas a cultura norte americana e inglesa. Verifica-se, portanto, que ele dá atenção às demais culturas, transmitindo novamente a pluriculturalidade nos léxicos.

Há questões sobre o dialeto negro nos Estados Unidos e sobre como o preconceito linguístico afeta esse tipo de linguagem. $O$ autor escolhe colocar no texto os posicionamentos de três pessoas negras qualificadas sobre o assunto, entre elas duas mulheres, como já demonstrado na imagem 2 e também ilustra mulheres negras nas profissões de médica, cientista, estudante. Os léxicos demonstram uma quebra das ideologias racistas presentes nos materiais, novamente de acordo com a dimensão textual de Fairclough (2001).

Posteriormente, os benefícios dessa representação positiva encontram-se na segunda dimensão do quadro tridimensional, a prática discursiva. Segundo Fairclough (2001), ela é sobre a distribuição, produção e consumo dos textos. O livro didático de Tilio é produzido e distribuído para as escolas Estaduais e é consumido por alunos que são adolescentes, estudando no segundo ano do ensino médio.

O livro é utilizado por três turmas em uma escola pública, com uma média de 70 estudantes no total. $\mathrm{O}$ autor transmite aos alunos imagens e textos com variedades de pessoas e culturas, atividades críticas e oportunidades para o professor abrir discussões em sala de aula sobre vários assuntos importantes da atualidade, e como a pluriculturalidade. Os adolescentes, dessa forma, são capazes de adquirir senso crítico. Tilio, ao escrever o livro, estava ciente do seu público e o organizou de maneira a influenciar positivamente o pensamento dos alunos.

A última e terceira dimensão do Modelo Tridimensional de Fairclough (2001), a social, investiga as hegemonias presentes no discurso, sendo elas intencionais ou não. Ele explica sobre a terceira dimensão e como as relações de poder podem reproduzir ou desafiar as hegemonias existentes:

[...] essas relações de poder reproduzem, reestruturam ou desafiam as hegemonias existentes - como um modelo - uma forma de analisar a própria prática discursiva como um modo de luta hegemônica, que reproduz, reestrutura ou desafia as ordens de discurso existentes. Isso fortalece o conceito de investimento político das práticas discursivas e, já que as hegemonias têm dimensões ideológicas e uma forma de avaliar o investimento ideológico das práticas discursivas. (FAIRCLOUGH, 2001, p. 126). 
Portanto, os discursos escritos por grupos em posição de poder podem reproduzir as hegemonias existentes ou desafiar e se opor a estes pensamentos. A terceira dimensão do Modelo Tridimensional (FAIRCLOUGH, 2001), a prática social, investiga como as ideologias e ideias hegemônicas são trabalhadas pelo autor.

O livro didático é um instrumento que transmite muito poder e é inquestionado pelos seus usuários por fazer parte da instituição escolar, ambiente de autoridade.

O livro didático, geralmente o primeiro contato do sujeito com as práticas de letramento em ambiente formal ou escolar, detém uma posição ainda mais marcante e que o fortalece em relação a outros materiais, pelo fato de estar respaldado por uma instituição extremamente valorizada pela sociedade e cuja autoridade é considerada inquestionável - a escola. (PEREIRA, 2009, p. 4).

A escola, portanto, é uma instituição respeitada e que retém poder por ser valorizada. Possui grande autoridade e o livro didático é instrumento essencial nas salas de aula. Van Dijk (2009), em seu livro Discurso e poder discute sobre o poder social, e que instituições ou grupos que detém poder tem controle sob os demais.

Os grupos possuem (maior ou menor) poder se forem capazes de exercer (maior ou menor) controle sobre os atos e mentes dos (membros de) outros grupos. Essa habilidade pressupõe a existência de uma base de poder que permita o acesso privilegiado aos recursos sociais escassos, tais como a força, o dinheiro, o status, a fama, o conhecimento, a informação, a "cultura" ou, na verdade, as várias formas públicas de comunicação e discurso. (VAN DIJK, 2009, p. 117).

Rogério Tilio, em seu livro didático, busca quebrar e desafiar as hegemonias normalmente difundidas por outros materiais. Não há nenhum trecho em que esteja explícito um posicionamento hegemônico, mesmo que não intencional. Há, pelo contrário, uma quebra das ideologias racistas e sexistas.

O padrão nos demais livros didáticos é, normalmente, branco e eurocentrista, ilustrando estereótipos de pessoas negras. Tílio se afasta desse modelo. Silva (2011) escreve sobre esse fato em materiais de inglês e a falta de representação de material pluricultural.

O sistema de ensino brasileiro, com seu currículo eurocêntrico e seus materiais pedagógicos, a não ser nos espaços da sala de aula, onde o currículo pode ser construído pluricultural, a partir da atuação de determinados professores, pouca vontade política tem de representar a diversidade étnico-racial e cultural do povo brasileiro. (SILVA, 2011, p. 94). 
O autor, quebrando essa hegemonia, faz representações de várias culturas, raças e gêneros, inclusive de mulheres negras, foco desta análise. Rogério Tilio, como mencionado no capítulo anterior, realiza em seus trabalhos acadêmicos estudos sobre a falta de representação no livro didático e repudia o eurocentrismo, a ideia de que a vida é perfeita nos Estados Unidos e na Inglaterra. Ele critica essa postura:

Existe uma tendência a se reduzir o mundo a Estados Unidos e Europa. O espaço para outras culturas, quando existe, é bastante simplista, limitando-se a mencionar algumas características culturais, na maioria das vezes estereotipantes. A pluralidade cultural a que os livros se propõem resume-se, em geral, a tratar alguns aspectos referentes a outros países de forma superficial e insuficiente, reduzindo esses países e a diversidade inerente a cada um deles ao que eles têm de turístico ou de cotidiano (TILIO, 2010, p. 182).

Um exemplo do livro em que o autor expande os horizontes além de Estados Unidos e Europa é no exercício em que são demonstrados alguns teatros musicais. Tilio (2016) não se limita apenas aos sucessos americanos da Broadway como "Cats" ou "Os Miseráveis", mas igualmente, faz menção a uma peça brasileira com teor crítico, baseada no livro "Casa Grande e senzala" de Gilberto Freyre.

A África também é exposta no material, demonstrando uma imagem positiva do continente, em oposição a livros que consideram culturas diferentes como "exóticas" ou as estereotipando. Faz reflexões sobre a corrupção, a cultura, o governo e a invasão dos europeus ao continente, o avaliando criticamente e não apenas com base nos estereótipos existentes.

Com base na terceira e última dimensão do Modelo Tridimensional de Fairclough (2001), o posicionamento de Tilio (2016), no livro didático Voices Plus, desafia as hegemonias existentes. Ele está em uma posição de poder e se aproveita dessa condição para reproduzir no livro questões sem preconceitos ou estereótipos de gênero ou raça.

No material didático organizado por ele e analisado neste trabalho, observa-se uma grande diferença em relação ao conteúdo de outros livros didáticos de língua inglesa, com relação a representar minorias ou oferecer discussões aos alunos. Enquanto em vários outros não há quase nenhuma representação positiva de mulheres negras, como apontado no capítulo anterior, o de Tilio (2016) as representa em posição de igualdade.

Desse modo, verificou-se que Tilio (2016) realmente reflete, em seu trabalho como organizador do livro didático Voices Plus para o segundo ano do Ensino Médio, os estudos feitos por ele sobre representação de minorias, expondo os alunos, que são adolescentes estudantes do ensino médio, a imagens positivas de mulheres negras e de outras pessoas normalmente excluídas, além das discussões construtivas e pluriculturais propostas por ele. 


\section{ConsideraçõEs finais}

Os resultados da análise, segundo o modelo tridimensional de Fairclough (2001), mostram que as imagens e textos do livro didático Voices Plus de Rogério Tilio (2016), respeitam as mulheres negras e não as colocam em posição de inferioridade às demais pessoas. Em relação às figuras que em elas aparecem, elas são representadas como médicas, professoras, diretoras, estudantes, quebrando estereótipos preconceituosos anteriores em que as mulheres, principalmente as negras, eram apenas representadas em posições de empregadas, donas de casa, etc.

Também foi constatado que o livro didático é normalmente o único instrumento disponível em sala de aula para ensino de língua estrangeira nas escolas brasileiras e, por essa razão, torna- se poderoso e o seu conteúdo é tido como uma verdade incontestável. O ambiente escolar também retém muito poder e é extremamente valorizado pela sociedade por ser o primeiro contato dos indivíduos com a educação.

Os livros didáticos, por reterem esse poder, normalmente transmitem ideias hegemônicas e não promovem igualdade em suas imagens e textos e, além de colocar mulheres negras e outras minorias em posição de inferioridade ou de invisibilidade, também não promovem discussões construtivas ou estimulam o senso crítico do aluno.

Em contrapartida, Rogério Tilio (2016) usufrui da posição privilegiada de escrever um livro didático para oferecer um conteúdo inclusivo, com representações de diversas culturas e raças, além de apresentar atividades construtivas que encorajam o questionamento.

O LD de Tilio (2016) obteve um grande avanço em relação a outros materiais, um passo positivo para maior representatividade, menos estereotipização, invisibilização de mulheres negras e outras minorias. O autor as coloca em posição de destaque, influenciando positivamente os estudantes que utilizam o livro.

As mulheres e negros compõem, estatisticamente, mais da metade da população brasileira, portanto, é justo que estejam em papéis igualitários aos homens e brancos. Isso não ocorre, pois as ideologias hegemônicas propostas pelos grupos que detém o poder no Brasil afetam as minorias. Há muitas mulheres negras em cargos altos, e é esperado que essa realidade se reflita nos livros didáticos.

Essa representação é essencial na identidade e desenvolvimento dos alunos e para construir uma sociedade mais justa, com menos preconceito. Tilio (2016) consegue, em seu livro, quebrar o padrão preconceituoso anterior, colaborando para a formação de cidadãos mais conscientes.

Por fim, é necessário ressaltar que ainda há muita pesquisa a ser realizada sobre o tema proposto neste trabalho, para que, assim, seja possível que todos os livros didáticos tenham representatividade, como ocorre no material de Tilio (2016). É necessário continuar os estudos e análises de livros didáticos para que haja mudança na estereotipização e invisibilização de minorias. 


\section{REFERÊNCIAS}

DIJK, T. A. V. Discurso e Poder. São Paulo: Contexto, 2008.

FAIRCLOUGH, N. Discurso e Mudança Social. 2.ed. Brasília: Editora Universidade de Brasília, 2001.

FARIAS, K. C.; FERREIRA, A. de J. Livro Didático de Língua Inglesa e o que os Discursos Escritos Revelam sobre Identidade Racial. Travessias, vol. 8. N. 3, 2014, p. 56-75. ISSN: 1982-5935

FERREIRA, A de J; CAMARGO, M. Racismo cordial no livro de língua inglesa aprovado pelo pnld. Revista da Associação Brasileira de Pesquisadores(as) Negros(as) - ABPN, v. 6, p. 177, 2013.

GIL, A. C. Métodos e técnicas de pesquisa social. São Paulo: Atlas, 1991.

PEREIRA, A. L. Representações de gênero em livros didáticos de língua estrangeira e discursos gendrados em sala de aula. In: III EDIPE - Encontro Estadual de Didática e Prática de Ensino, 2009, Anápolis.

RODRIGUES-JÚNIOR, A. S. Análise crítica do discurso: modismo, teoria ou método? Rev. Brasileira de linguística aplicada. Online, 2009, vol.9, n.1, p.99-132.

SENE, R. A. R.; FERREIRA, A. de J. O que as pesquisas recentes revelam acerca das identidades de gênero, de raça e de sexualidade nas aulas de língua inglesa. Polifonia, v. 25, n. 37.2, p. 311$334,2018$.

SILVA, A. C. da. A representação social do negro no livro didático: o que mudou? Por que mudou? Salvador: EDUFBA, 2011. p. 182.

SILVA, I. S. Relações raciais nos livros didáticos de língua portuguesa 13 anos após a lei 10.639/03. In: XIII Congresso Nacional de Educação, 2017. XIII Encontro Nacional de Educação. Curitiba: PUC/PR. p. 18003-18020.

TILIO, R. C. A representação do mundo no livro didático de inglês como língua estrangeira: uma abordagem sócio-discursiva. The Especialist. São Paulo: PUC/SP, 2010, v. 31. p. 167-192. TILIO, R. C. Voices Plus 2 - Livro do Aluno. 1.ed. São Paulo: Richmond Educação LTDA, 2016. v. 1. p. 209.

TILIO, R. C. Questões de gênero e sexualidade em livros didáticos: ainda tabus? In: XVI Semana Interdisciplinar de Estudos Anglo-Germânicos, 2009, Rio de Janeiro. XVI SIEAG: Línguas, literaturas e mídias - Caderno de resumos. Rio de Janeiro: Faculdade de Letras - UFRJ, 2009.

WATTHIER, L. A discriminação racial presente em livros didáticos e sua influência na formação da identidade dos alunos. Revista Urutágua, Maringá, n.16, p.47-54, ago./nov. 2008.

Recebido para publicação em 11 de Janeiro de 2020. Aceito para publicação em 2 de Março de 2020. 